Eur J Clin Chem Clin Biochem

1995; 33:83-86

(c) 1995 Walter de Gruyter \& Co.

Berlin $\cdot$ New York

\title{
Determination of Faecal Fat by Near-Infrared Spectroscopy
}

\author{
By Otto Bekers, Cobie Postma and Arnold J. P. F. Lombarts \\ Department of Clinical Chemistry and Haematology, Leyenburg Hospital, The Hague, The Netherlands
}

(Received September 19/November 30, 1994)

Summary: The applicability of near-infrared spectroscopy to determine the amount of fat in faeces has been investigated. Near-infrared spectroscopy was favourably compared with the well known titrimetric method (Van de Kamer et al., J Biol Chem 1948; 177:347-55). A good correlation between near-infrared spectroscopy and the titrimetric method was found. The measurement of faecal fat by near-infrared spectroscopy is found to be more precise than the manual method. Moreover, near-infrared spectroscopy is shown to be a very simple and rapid method for measuring fat in faeces. However, it was shown that performing one's own calibration curve is necessary. Due to this necessity and the costs of the apparatus application of near-infrared spectroscopy is especially advantageous in laboratories with a substantial amount of samples to be analysed.

\section{Introduction}

The determination of fat in faeces plays an important role in the diagnosis of steatorrhoea (1). The method used to quantify faecal fat in clinical chemical laboratories is mostly a titrimetric one, as described by Van de Kamer et al. $(2,3)$. In this method the amount of fat is determined after alkaline hydrolysis, subsequent extraction of the free fatty acids with petroleum ether, and titration of the fatty acids with alkali. This method is imprecise, rather complex, tedious and time consuming. Since our hospital includes an Adult Cystic Fibrosis Centre, a substantial number of fat balances have to be performed leading us to look for a suitable alternative to the Van de Kamer method. One possibility is near-infrared reflectance analysis or near-infrared spectroscopy, a method increasingly used in clinical chemistry $(4-8)$.

The aim of the present study was to evaluate the use of near-infrared spectroscopy for the determination of faecal fat and to compare the obtained results with those of the Van de Kamer method. Initially our intention was to use a known published near-infrared spectroscopy calibration line for fat in faeces (4) and compare the obtained results with those of our Van de Kamer method.

\section{Patients and Methods}

Patients

Patients $(n=108)$ whose clinical picture suggested malabsorption or who suffered from a disease known to cause malabsorption, especially cystic fibrosis, were studied. Determination of faecal fat was performed on stools from three-day collections. Two days before and during collection patients were placed on a fat diet, varying from $60-100 \mathrm{~g}$ per day.

\section{Principles of near-infrared spectroscopy}

Only a short explanation of the near-infrared spectroscopy principles will be given here, since a comprehensive description is beyond the scope of this paper. In near-infrared spectroscopy, emitted radiant energy in the $750 \mathrm{~nm}$ to $2500 \mathrm{~nm}$ range of the spectrum is reflected from a sample and detected by the analytical instrument. The amount of reflected energy is dependent upon both the chemical and physical properties of the sample, represented by the molecular absorbances and scattering, respectively. Before near-infrared spectroscopy can be used as a quantitative method, special attention should be paid to the calibration procedure.

Near-infrared spectroscopy calibration analysis is performed by multiple regression between the logarithm of reciprocal reflectance $(\log 1 / R)$ over the entire spectrum and the concentration of the desired constituent. When generating calibration equations samples of known composition are used. It is important that at least 40 samples, well distributed over the whole required concentration range, are determined. Stepwise multiple regression statistics allow for the selection of calibration wavelengths which correlate most closely to the analyte concentrations of these samples. Near-infrared measurements in complex matrices, such as faeces, are usually 
performed at five or more different wavelengths. Apart from the wavelengths were the analyte absorbs, other wavelengths are used to correct for sample changes in background reflectance and interfering substances. Once optimal wavelengths are selected and scaling factors (F) corresponding to each selected filter are calculated, a calibration equation (Eq. 1) can be derived $(6,9)$.

$$
\begin{aligned}
c=Z & +F_{1} \log 1 / R_{1} \\
& +F_{2} \log 1 / R_{2}+\ldots+F_{n} \log 1 / R_{n}
\end{aligned}
$$

where $c$ is the concentration of the analyte, $R_{n}$ is the reflectance for filter $n, F_{n}$ is the scaling or weighting factor for each filter and $\mathrm{Z}$ is a constant for bias correction, which is the absorbance intercept at a faecal fat concentration of zero.

The near-infrared spectrometer may now be used to determine unknown samples for the quantity of the analyte of interest.

\section{Methods}

Stools were weighed, homogenised and the fat content was determined titrimetrically as well as by near-infrared spectrometry.

At least one sample per patient was stored at $-20^{\circ} \mathrm{C}$ for further analysis.

The titrimetric analyses were performed as described earlier by Van de Kamer et al. $(2,3)$. Intralipid ${ }^{\circledR} 10 \%$ (Kabi Pharmacia, Sweden) was routinely used for assessment of the accuracy of the Van de Kamer method, and was treated in the same way as the faecal fat samples.

The near-infrared spectrometric analyses were carried out on a InfraAlyser ${ }^{\circledR}$ Model 400 (Bran and Luebbe, Maarssen, The Netherlands) connected to an IBM personal computer PS2 Model 55SX. The software APC ${ }^{\circledR}$ was supplied by Bran and Luebbe.

About five grams of homogenate were placed on a disposable cup (Bran and Luebbe) and smoothed flat with a glass slide. The prepared sample cup was placed on an interchangeable sample drawer and thereupon pushed into the InfraAlyser ${ }^{\circledR}$. The result was displayed within one minute.

\section{Statistical analysis}

Regression analyses for method comparisons were done by using the orthogonal Passing \& Bablok procedure $(10,11)$.

\section{Results}

\section{Calibration of the near-infrared spectrometer}

The calibration equation reported in an earlier study of Koumantakis \& Radcliff (4) was fed into the InfraAlys-

Tab. 1 The essential results of multilinear regression analysis for the determination of fat in faeces by near-infrared spectroscopy found in our study of 73 samples

\begin{tabular}{lc}
\hline Wavelength $(\mathrm{nm})$ & Scaling factor \\
\hline 1445 & 6.63 \\
1680 & -81.6 \\
1734 & 159.0 \\
1778 & -58.3 \\
2208 & -48.6 \\
2310 & 24.2 \\
$\mathrm{Z}^{\mathrm{a}}$ & 2.71 \\
\hline
\end{tabular}

a $\mathrm{Z}$ is the bias correction, see text for further explanation
$\mathrm{er}^{\circledR}$ and 35 samples were determined for the content of fat in faeces. A regression analysis between our results obtained with the method of Van de Kamer and the nearinfrared spectrometry, using the above mentioned equation (4), was performed and this resulted in a correlation coefficient of only 0.34 . Therefore' we decided to perform a complete calibration study. The results of this study are presented in table 1 . For the calibration 73 samples were used. These results have been obtained by scanning the near-infrared spectrum of each sample in the region from $1100 \mathrm{~nm}$ to $2500 \mathrm{~nm}$ (in steps of about $50 \mathrm{~nm}$, by employing the wavelengths of the various filters) and selecting those wavelengths and scaling factors (F) from the total data that corresponded most closely to the fat content of the faecal samples. These complex multivariate regression analyses $(6,9,12,13)$ were performed by the software program APC ${ }^{\circledR}$, which is supplied by the InfraAlyser ${ }^{\circledR}$. The values from table 1 can be substituted in equation 1 (Eq. 1), resulting in the following calibration curve (Eq. 2):

$$
\begin{aligned}
& c=2.71+6.63 \log 1 / R_{1445} \\
& \text { - } 81.6 \log 1 / R_{1680} \\
& +159 \log 1 / R_{1734} \\
& \text { - } 58.3 \log 1 / \mathrm{R}_{1778} \\
& \text { - } 48.6 \log 1 / R_{2208} \\
& +24.2^{\circ} \log 1 / R_{2310}
\end{aligned}
$$

\section{Correlation study}

Figure 1 shows the relationship between the faecal fat content of 35 samples analysed both with the titrimetric method of Van de Kamer and with near-infrared spectrometry, using the calibration curve as described in

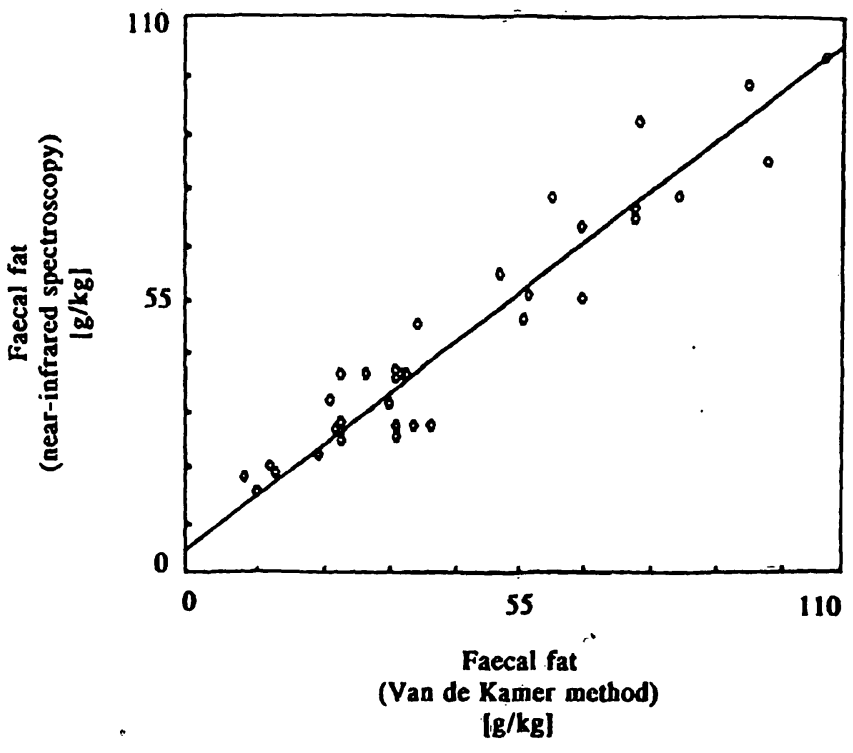

Fig. 1 Correlation between faecal fat results $(g / \mathrm{kg})(\mathrm{n}=35)$, measured by near-infrared spectroscopy.and the Van de Kamer procedures; $y=0.89 x+0.76 ; r=0.97 ; p<0.01$. 
Tab. 2 Imprecision of the faecal fat assays by the Van de Kamer. procedure and the near-infrared method

\begin{tabular}{llllll}
\hline & \multicolumn{2}{l}{ Van de Kamer } & \multicolumn{2}{c}{$\begin{array}{l}\text { Near-infrared } \\
\text { spectroscopy }\end{array}$} \\
\cline { 2 - 3 } & intra-day & inter-day & & intra-day & inter-day \\
\hline$\overline{\mathrm{x}}^{\mathrm{a}}(\mathrm{g} / \mathrm{kg})$ & 45 & 62 & & 51 & 54 \\
$\mathrm{SD}^{\mathrm{b}}$ & 4.1 & 7.2 & & 1.7 & 3.2 \\
$\mathrm{CV}^{\mathrm{c}}(\%)$ & 8.9 & 11.3 & & 3.3 & 5.9 \\
\hline
\end{tabular}

a $\bar{x}$ is the mean value of ten determinations

b $\mathrm{SD}$ is the standard deviation

c $\mathrm{CV}$ is the coefficient of variation

equation 2. The correlation between both methods, calculated as described by Passing \& Bablok $(10,11)$, is $\mathrm{y}=0.89 \mathrm{x}+0.76(\mathrm{y}=$ near-infrared spectrometry; $\mathrm{x}=$ Van de Kamer). The correlation coefficient ( $r$ ) was 0.97 and the standard error of the estimate (SEE) was found to be $4.8 \mathrm{~g}$.

\section{Imprecision of the results}

In table 2 the results of the intra-day and inter-day imprecision are summarised. The results of the inter-day imprecision were obtained during a three-week period. It will be obvious that the near-infrared spectrometric procedure is far more precise than the Van de Kamer method.

\section{Homogenisation and stability}

The coefficient of variation of samples analysed without previous homogenisation were all found to be in the range of $15-22 \%$ (tab. 3). This means that for obtaining precise results, mixing of stools before analysing with near-infrared spectrometry remains a prerequisite.

Stools obtained from patients with diarrhoea (exceeding approximately $75 \%$ water content) were found to be unsuitable for near-infrared spectrometric analyses.

The stability of some samples has been investigated. A sample may be stored at room temperature for a maxi-

Tab. 3 Some results of faeçal fat determinations by near-infrared spectroscopy without previous homogenisation of the samples before analysis

\begin{tabular}{|c|c|c|c|c|}
\hline & \multicolumn{4}{|c|}{ Collectives } \\
\hline & 1 & 2 & 3 & 4 \\
\hline $\begin{array}{l}\bar{x}^{\mathrm{a}}(\mathrm{g} / \mathrm{kg}) \\
\mathrm{SD}^{\mathrm{b}} \\
\mathrm{CV}^{\mathrm{c}}(\%)\end{array}$ & $\begin{array}{c}12 \\
2.6 \\
21.7\end{array}$ & $\begin{array}{c}26 \\
3.9 \\
15.0\end{array}$ & $\begin{array}{l}54 \\
10 \\
18.5\end{array}$ & $\begin{array}{l}96 \\
21 \\
21.8\end{array}$ \\
\hline
\end{tabular}

${ }^{a} \bar{x}$ is the mean value of ten determinations

b $\mathrm{SD}$ is the standard deviation

c $\mathrm{CV}$ is the coefficient of variation mum of five days before analysis. However, it is obviously preferable to store the samples for a few days in a refrigerator. At $-20^{\circ} \mathrm{C}$ samples can be stored, without changing the fat content, for at least five months. A sample can be thawed and afterwards be frozen again at least three times without influencing the outcome of the result. Six samples were analysed and coefficients of variation were all below $6 \%$ (this result is comparable with the inter-day coefficient of variation of $5.9 \%$ in tab. 2).

\section{Discussion}

The near-infrared spectrometric technique applied to the analysis of faecal fat is shown to be a suitable method to determine fat in faeces. Near-infrared spectroscopy offers, compared with the Van de Kamer method, the following benefits: the imprecision is lower; no reagents are necessary; the analysis-time is very short and the method is simple to perform. Homogenisation, which is one of the unpleasant and time consuming actions in the procedure seems to be a prerequisite, since coefficient of variations are high (tab. 3). However, for a first screening of malabsorption, homogenisation may be avoidable. In this situation we would suggest taking at least nine specimens in different parts of the same stool collection ( $\mathrm{CV}=15-22 \%)$. If the mean value $\pm 2 \mathrm{~S}$. D. is within the reference range the diagnosis of steatorrhoea is unlikely. This conclusion is in agreement with an earlier study by Benini et al. (14), who suggest that a normal fat content obtained with near-infrared spectrometry in non-homogenised samples rules out the diagnosis of steatorrhoea.

The main disadvantage of the near-infrared spectrometric method is the necessity to perform one's own calibration curve: we found a coefficient of correlation of only 0.34 by using the equation of Koumantakis \& Radcliff (4), compared with a coefficient of correlation of 0.97 using our own calibration curve. This discrepancy may be due to matrix effects of the stools (differences of food composition in Australia (4) and The Netherlands), performance of the spectroscope and/or, not least of all, the accuracy of the Van de Kamer method. Unfortunately a golden standard method for stool analysis does not exist, nor are calibrators or external quality assessment schemes available. Therefore, we have routinely used Intralipid ${ }^{\circledR}$ for the assessment of the accuracy of the Van de Kamer method. In our laboratory this suspension has been proven to be suitable for this purpose.

Since we have shown that samples at $-20^{\circ} \mathrm{C}$ are stable for at least five months, these samples are suitable for the quality control of the near-infrared spectrometric method, which is important because Intralipid ${ }^{\circledR}$ is not 
suitable for near-infrared spectrometric analysis. Another disadvantage of the near-infrared spectrometric method is that very aqueous stools (diarrhoea) cannot be analysed due to interference, probably caused by the first and second overtones of the $\mathrm{O}-\mathrm{H}$ bond stretch of the water molecule $(6,9)$.

Since the apparatus is rather expensive the use of nearinfrared spectrometry seems most suitable in specialised centres, such as our Cystic Fibrosis Centre, or central-

\section{References}

1. Bolinn G, Fordtran JS. Fecal fat concentration in patients with steatorrhea. Gasteroenterology 1980; 87:319-22.

2. Van de Kamer JH, Ten Bokkel Huinink H, Weyers HA. Rapid determination of fat in feces. J Biol Chem 1948; 177:347-55.

3. Van de Kamer JH. Total fatty acids in stool. In: Selingson, editor. Standard Methods of Clinical Chemistry, Vol III. New York: Academic Press, 1958:34-9.

4. Koumantakis G, Radcliff FJ. Estimating fat in feces by nearinfrared reflectance spectroscopy. Clin Chem 1987; 33:502-6.

5. Peuchant E, Salles C, Jensen R. Value of a spectroscopic "fecalogram" in determining the aetiology of steatorrhea. Clin Chem 1988; 34:5-8.

6. Hall JH, Pollard A. Near-infrared.spectroscopy: A new dimension in clinical chemistry. Clin Chem 1992; 38:1623-31.

7. Hall JH, Pollard H. Near-infrared spectroscopic determination of serum total proteins, albumin, globulins and urea. Clin Biochem 1993; 26:483-90.

8. Robinson MR, Eaton RP, Haaland DM, Koepp GW, Thomas EV, Stallard BR, et al. Noninvasive glucose monitoring in diabetic patients: a preliminary evaluation. Clin Chem 1992; 38:1618-22.

9. Alfa-Leval group, Bran and Luebbe. Reference manual analyzing technologies. Publication no. TL8-4546-10. Theory of ised laboratories with a substantial amount of samples to be analysed. In such circumstances the advantages of the method are quite obvious, particularly in light of the budgetary restraints laboratories all over the world are experiencing. Furthermore, near-infrared spectrometry is a technique which in the near future will probably be used on a larger scale for other determinations in clinical chemistry (6-8).

near-infrared reflectance analysis. New York: Elmsford, 1987; A1:1-32.

10. Passing $\mathrm{H}$, Bablok W. A new biometrical procedure for testing the equality of measurements from two different analytical methods. J Clin Chem Clin Biochem 1983; 21:709-20.

11. Passing $\mathrm{H}$, Bablok W. Comparison of several regression procedures for method comparison studies and determination of sample sizes. J Clin Chem Clin Biochem 1984; 22:431-45.

12. Beebe K, Kowalski BR. An introduction to multivariate calibration and analysis. Anal Chem 1987; 59:1007-17.

13. Martens H, Naes T. Multivariate calibration. New York: John Wiley and Sons, 1989.

14. Benini L, Caliari S, Guidi GC, Vaona B, Talamini G, Vantini I et al. Near infrared spectroscopy for faecal fat measurement: comparison with conventional gravimetric and titrimetric methods. Gut 1989; 30:1344-7.

\section{Dr. O. Bekers}

Leyenburg Hospital

Department of Clinical Chemistry and Haematology

P. O. Box 40.551

NL-2504 LN The Hague

The Netherlands 